\title{
Lifecourse Urbanization, Social Demography, and Health Outcomes among a National Cohort of 71,516 Adults in Thailand
}

\author{
Vasoontara Yiengprugsawan, ${ }^{1}$ Bruce K. Caldwell, ${ }^{1}$ Lynette L.-Y. Lim, ${ }^{1}$ \\ Sam-ang Seubsman, ${ }^{2}$ and Adrian C. Sleigh ${ }^{1}$ \\ ${ }^{1}$ National Centre for Epidemiology and Population Health, The Australian National University, Canberra ACT 0200, Australia \\ ${ }^{2}$ School of Human Ecology, Sukhothai Thammathirat Open University, Nonthaburi 11120, Thailand
}

Correspondence should be addressed to Vasoontara Yiengprugsawan, vasoontara.yieng@anu.edu.au

Received 4 March 2011; Revised 15 June 2011; Accepted 13 July 2011

Academic Editor: Shirlena Huang

Copyright (C) 2011 Vasoontara Yiengprugsawan et al. This is an open access article distributed under the Creative Commons Attribution License, which permits unrestricted use, distribution, and reproduction in any medium, provided the original work is properly cited.

\begin{abstract}
We examine the influence of urbanization on household structure, social networks, and health in Thailand. We compare lifetime urban or rural dwellers and those who were rural as children and urban as adults. Data derived from a large national cohort of 71,516 Sukhothai Thammathirat Open University adult students participating in an on-going longitudinal study of the healthrisk transition in Thailand. The rural-urban group, one-third of cohort households, was significantly different from other groups (e.g., smaller households). The rural-rural and the urban-urban groups often were the two extremes. Urbanization, after adjusting for covariates, was a risk factor for poor overall health and depression. Urbanization is a mediator of the health-risk transition underway in Thailand. Health programs and policies directed at transitional health outcomes should focus on the health risks of the urbanizing population, in particular smoking, drinking, low social trust, and poor psychological health.
\end{abstract}

\section{Background}

Rapid urban growth has occurred in many cities of the developing world affecting urban housing, sanitation, transportation, and the environment [1-3]. This transformation is largely driven by rural-urban migration and has profound implications for the general health and well-being of the population. A link between urbanization and health has been reported for different populations and locations [4-10].

Although still a majority rural country, Thailand has been rapidly urbanizing in the past few decades [11-13]. Migration has been one of the main contributors to urbanization. Rural to urban migration has been a response to the unequal distribution of economic opportunities and could alleviate poverty [14]. It is estimated that Thailand was about $37 \%$ urbanized in 1995, at the peak of the economic boom before the Asian financial crisis [15]. Within the next two decades, the urban population defined more widely as those who live in municipal and periurban areas is projected to increase from 39 percent of the total population in 2007 to 47 percent in 2027 [16].
Differences in household structure have important implications for social support and health. For example, one study has shown the importance of social networks and familial support in Thailand, particularly elderly coresidence with an adult child and consequent intergenerational support in the household [17]. Another study has shown continued social contact among rural Northeastern Thais who migrated to cities, especially singles living away from home [18]. A Chinese study also found that older parents living in threegeneration households had better psychological well-being than those living in single-generation households [19].

For our research on the health-risk transition underway in middle-income Thailand, in 2005 we recruited a large national cohort of Thai adults for longitudinal study $(n=$ $87,134)$. The baseline data already revealed that urbanization is profoundly associated with the health-risk transition [20]. For example, compared to those who remain in rural areas, the urban migrants generally have more income and assets but worse diets, less physical and social activity, and more 
overweight and obesity. Many of these transitional phenomena noted above are linked to changes in the household social and physical environment.

In order to understand further the dynamics and consequences of urbanization, this paper focuses on household level structural features associated with urban migration in the study cohort and expected to have substantial impacts on health-risk transitions noted in earlier analyses. To enable informative contrasts, we distinguish between those who have been urban or rural dwellers for most of their life and those who were rural as children (aged 12 years) and urban as adults, and we link this lifecourse urbanization status to health and social outcomes.

\section{Data and Methods}

The data derive from a cohort of 87,134 distance-learning adults enrolled at Sukhothai Thammathirat Open University (STOU) who completed a comprehensive baseline questionnaire in 2005. The baseline characteristics of cohort participants compared to the population of Thailand have been reported [21]. The 20-page baseline questionnaire covered a wide range of topics including family background, demographic, socioeconomic, and geographic information, dietary intake, health-risk behaviours, injuries, health status, and use of health services. Analysis here is restricted to young and middle-aged adults between 20 and 39 years, totaling 71,516 people.

Cohort members are working people and broadly represent the general population geographically and socioeconomically although they are better educated than average Thais of the same age and sex; 54\% were females and the median age was 29 years. In this paper, we describe various attributes which affect household structural features including head of household, number of members, number of those aged less than 15 years, house type, permanent and/or working home, vehicle and house ownership, and travel time to work.

In the 2005 baseline questionnaire, cohort members were asked: "where is your home located now?" as well as "where was your home when you were 10-12 years old?" Possible responses were "countryside" (ในชนบท or "naichon-na-bot") and "city/town" (ในเมือง or "nai-muang"). In Thai, "nai" means "in," "chon-na-bot" means "rural," and "muang" means "urban" in administrative government categories. We analyzed the effect of urbanization based on lifecourse residence (at age 10-12 years and in 2005) with urbanization status classified as "rural-rural," "ruralurban," "urban-rural," and "urban-urban". The "urbanrural" group was relatively small (4\%) and was older [20]. We excluded them from this analysis because they did not provide information on the dominant rural-urban migration trend and they will be the subject of further study. Other variables available for analysis that could affect household structure included age-sex group, marital status, income levels, household assets (replacement value), and job types.

Health outcomes included self-assessed health ("poor" or "very poor") using the first question of the Medical Outcomes Short Form instrument (SF8) [22]. We also measured psychological distress based on three questions of the standard Kessler 6 instruments (feeling "nervous," "restless," or "everything was an effort"); each question was graded on a 5-point scale ( 1 all of the time, 2 most of the time, 3 some of the time, 4 a little of the time, 5 none of the time). For our analysis of psychological distress, if the average combined responses for the three Kessler questions was $\leq 2$, the respondent was classified as psychologically distressed [23]. We also recorded the prevalence of doctordiagnosed hypertension and depression-anxiety. Obesity was categorised using body mass index $(B M I \geq 25)$ in accordance with the International Obesity Task Force cut-offs for Asian population [24]. In addition, we also included information on health behaviours (current smoking and alcohol drinking), as well as a variety of social outcomes including social interactions, support from family or neighbours, and social trust.

2.1. Model Selection. We focus our initial description on several standardized measures, including various health and social outcomes. For the analyses of three key health outcomes (self-assessed health, depression, and hypertension), we construct multivariate models that investigate the effect of lifecourse urbanization along with an array of sociodemographic, household, social, and behavioral factors.

Covariates included in the final analyses were lifecourse urbanization, age, sex, marital status, household size, income, health-risk behaviours (cigarette smoking and alcohol drinking), and social trust. On general epidemiologi-cal principles (person-place-time influences on health outcomes) each of these covariates would be expected to influence the health outcomes investigated [25]. Indeed, all modeled covariates have been shown in our previous reports from this cohort to have substantial influences on various health outcomes [26, 27].

2.2. Data Processing and Statistical Analysis. Data scanning and editing were done using Thai Scandevet, SQL and SPSS. For analysis we used Stata version 9 reporting odds ratios (OR) and 95\% confidence intervals based on multivariate logistic regression. Individuals with missing data for analyses presented here were excluded so totals vary a little according to the information available. Missing data usually involved $1 \%$ or less of observations, and, reflecting the large size of the cohort, our results were stable.

2.3. Ethical Considerations. Ethics approval was obtained from Sukhothai Thammathirat Open University Research and Development Institute (protocol 0522/10) and the Australian National University Human Research Ethics Committee (protocol 2004344). Informed written consent was obtained from all participants.

\section{Results}

3.1. Basic Description of Cohort Members. The demographic and socioeconomic characteristics of cohort members by lifecourse urbanization (childhood and current residence) 
TABLE 1: Thai cohort sociodemographic characteristics by lifecourse urbanization, 2005.

\begin{tabular}{|c|c|c|c|c|c|}
\hline \multirow{2}{*}{ Cohort characteristics } & & \multirow[t]{2}{*}{ Overall } & \multicolumn{3}{|c|}{ Lifecourse urbanization* (\%) } \\
\hline & & & Rural-rural & Rural-urban & Urban-urban \\
\hline & $N$ & 71,516 & $45.3(32,006)$ & $31.9(22,591)$ & $18.8(13,267)$ \\
\hline \multicolumn{6}{|l|}{ Demographic characteristics } \\
\hline \multicolumn{6}{|l|}{ Age-sex } \\
\hline \multicolumn{6}{|l|}{ Males } \\
\hline $20-29$ yrs & 16,872 & 23.6 & 25.4 & 22.1 & 22.1 \\
\hline $30-39$ yrs & 13,745 & 19.2 & 18.8 & 21.0 & 16.5 \\
\hline \multicolumn{6}{|l|}{ Females } \\
\hline $20-29$ yrs & 27,334 & 38.2 & 39.6 & 37.3 & 37.7 \\
\hline $30-39$ yrs & 13,563 & 19.0 & 16.1 & 19.7 & 23.7 \\
\hline \multicolumn{6}{|l|}{ Marital status } \\
\hline Single & 40,697 & 61.6 & 62.1 & 57.6 & 68.8 \\
\hline Partnered & 22,931 & 34.7 & 34.5 & 38.5 & 23.2 \\
\hline Divorced/divorced/widowed & 2,455 & 3.7 & 3.4 & 3.9 & 4.0 \\
\hline \multicolumn{6}{|l|}{ Household size } \\
\hline 1 & 1,971 & 2.8 & 1.7 & 4.8 & 2.0 \\
\hline $2-4$ & 34,534 & 48.4 & 46.2 & 51.4 & 48.1 \\
\hline $5+$ & 34,846 & 48.8 & 52.1 & 43.8 & 49.9 \\
\hline \multicolumn{6}{|l|}{ Socioeconomic characteristics } \\
\hline \multicolumn{6}{|l|}{ Monthly income (Baht/month) } \\
\hline$\leq 3000$ & 7,727 & 10.8 & 14.9 & 5.6 & 9.5 \\
\hline $3001-7000$ & 23,874 & 33.4 & 39.0 & 29.4 & 27.3 \\
\hline $7001-10000$ & 18,329 & 27.3 & 25.4 & 31.8 & 24.9 \\
\hline $10001-20000$ & 15,707 & 22.5 & 17.8 & 26.5 & 26.6 \\
\hline$>20000$ & 4,172 & 6.0 & 2.9 & 6.7 & 11.6 \\
\hline \multicolumn{6}{|l|}{ Household assets (Baht value) } \\
\hline $0-30000$ & 31,311 & 44.0 & 54.0 & 43.9 & 22.2 \\
\hline $30001-60000$ & 21,949 & 30.9 & 31.0 & 30.7 & 30.4 \\
\hline$>60000$ & 17,899 & 25.2 & 15.0 & 25.4 & 47.4 \\
\hline \multicolumn{6}{|l|}{ Job types** } \\
\hline Professionals & 9,780 & 18.5 & 18.1 & 16.7 & 22.2 \\
\hline Managers & 8,033 & 15.2 & 13.6 & 16.0 & 16.7 \\
\hline Skilled workers & 5,284 & 10.0 & 9.4 & 11.1 & 9.1 \\
\hline Office assistants & 21,074 & 39.8 & 39.8 & 38.4 & 42.6 \\
\hline Manual workers & 8,812 & 16.6 & 19.1 & 17.7 & 9.4 \\
\hline
\end{tabular}

* Urbanization group based on residence at age 12 and again when responding to the baseline questionnaire in 2005, column percents for each variable by urbanisation group.

** Multiple responses allowed.

are presented in Table 1. Overall, urbanization status was as follows: rural-rural (45.3\%), rural-urban $(31.9 \%)$, urbanurban $(18.8 \%)$, and urban-rural $(4.1 \%)$. As previously discussed, the last category was excluded from the subsequent analysis due to small numbers. Overall, 20-29-year olds predominated (23.6\% of males and $38.2 \%$ of females); the rest of the cohort was split equally between males and females aged $30-39$ years (19\% each). Single people made up the largest category $(61.6 \%)$, and divorced/separated/widowed were the least frequent $(3.7 \%)$, a contrast more pronounced among the urban-urban group (68.8\% versus $4.0 \%)$. One-person households were much more prominent in the rural-urban group $(4.8 \%)$ compared to other groups $(1.7 \%$ in the ruralrural and $2.0 \%$ in the urban-urban groups). The rural-rural group had the highest proportion of households larger than 5 persons $(52.1 \%$ in the rural-rural group versus $49.9 \%$ in the urban-urban group versus $43.8 \%$ in the rural-urban group).

There were substantial socioeconomic differentials among lifecourse urbanization groups. Income varied with only $2.9 \%$ of the rural-rural group earning more than $20,000 \mathrm{Baht} / \mathrm{month}$ compared to $6.7 \%$ of the rural-urban group and $11.6 \%$ of the urban-urban group. Household assets reflected these income differences and were valued at 30,000 Baht or less (or approximately \$US750) for $54.0 \%$ of the rural-rural group compared to $22.2 \%$ of the urbanurban group. Overall, the most frequent job type of cohort members was the office assistant category for all groups. But, compared to the rural-rural group, the urban-urban group 
TABLE 2: Household characteristics among cohort members by sex and lifecourse urbanization.

\begin{tabular}{|c|c|c|c|c|c|c|}
\hline \multirow{3}{*}{ Household characteristics } & \multicolumn{6}{|c|}{ Lifecourse urbanization* $(\%)$} \\
\hline & \multicolumn{2}{|c|}{ Rural-rural } & \multicolumn{2}{|c|}{ Rural-urban } & \multicolumn{2}{|c|}{ Urban-urban } \\
\hline & males & females & males & females & males & females \\
\hline \multicolumn{7}{|l|}{ Number of children ( $<15$ years) } \\
\hline 0 & 48.0 & 48.2 & 51.3 & 52.8 & 55.7 & 53.4 \\
\hline 1 & 26.5 & 27.9 & 26.2 & 25.3 & 24.0 & 25.1 \\
\hline 2 & 18.1 & 16.9 & 16.2 & 16.3 & 13.5 & 14.1 \\
\hline $3+$ & 7.5 & 7.1 & 6.3 & 2.1 & 6.7 & 2.8 \\
\hline \multicolumn{7}{|l|}{ Types of household } \\
\hline One adult with or without children & 2.0 & 0.9 & 4.9 & 3.2 & 2.0 & 1.4 \\
\hline Couple without children & 4.8 & 3.3 & 12.6 & 9.2 & 5.9 & 4.9 \\
\hline Couple with no children with parent/grandparents & 4.4 & 3.7 & 3.1 & 2.5 & 4.2 & 3.2 \\
\hline Couple with children and no parents/grandparents & 17.4 & 11.0 & 23.2 & 15.4 & 12.6 & 10.8 \\
\hline Couple with children and with parents or grandparents & 12.2 & 12.5 & 7.6 & 7.4 & 10.3 & 9.8 \\
\hline No spouse, no parents/grandparents & 6.6 & 5.6 & 11.5 & 15.4 & 8.1 & 7.9 \\
\hline No spouse, with parents/grandparents & 52.7 & 62.9 & 37.1 & 46.9 & 57.0 & 62.0 \\
\hline \multicolumn{7}{|l|}{ Head of household } \\
\hline Self & 26.2 & 6.7 & 46.5 & 14.5 & 27.6 & 11.6 \\
\hline Husband/wife & 0.8 & 14.8 & 0.8 & 24.9 & 0.6 & 16.3 \\
\hline Father & 47.9 & 56.0 & 31.5 & 35.6 & 44.5 & 42.4 \\
\hline Mother & 14.1 & 15.4 & 10.0 & 12.6 & 19.6 & 19.6 \\
\hline Father-in-law & 5.7 & 2.4 & 3.6 & 2.6 & 1.3 & 1.9 \\
\hline Mother-in-law & 2.1 & 1.0 & 1.6 & 1.2 & 0.8 & 0.6 \\
\hline Relatives/other males & 2.7 & 2.5 & 4.5 & 5.5 & 3.4 & 4.0 \\
\hline Relative/other females & 1.8 & 2.3 & 2.8 & 5.4 & 3.4 & 4.8 \\
\hline \multicolumn{7}{|l|}{ Living in the household** } \\
\hline Spouse/partner & 40.0 & 31.4 & 48.5 & 36.1 & 33.7 & 29.4 \\
\hline Adult son/daughter & 3.7 & 3.7 & 3.3 & 3.6 & 2.6 & 2.9 \\
\hline Adult brother/sister & 45.2 & 53.5 & 36.3 & 46.3 & 53.1 & 55.6 \\
\hline Parent & 65.4 & 75.9 & 43.7 & 52.6 & 68.2 & 71.5 \\
\hline Grandparent & 9.3 & 10.9 & 6.3 & 7.4 & 9.0 & 10.5 \\
\hline Other relative or in-law & 10.5 & 17.1 & 17.6 & 20.4 & 21.2 & 22.4 \\
\hline Nonrelative & 3.4 & 2.7 & 7.2 & 8.5 & 6.6 & 7.1 \\
\hline
\end{tabular}

*Urbanization group based on residence at age 12 and again when responding to the baseline questionnaire in 2005 , column percents for each variable by urbanization group.

$* *$ Multiple responses allowed.

had the highest proportion of professionals and managers (38.9\% versus $31.7 \%$ ) and the lowest proportion of manual workers (9.4\% versus $19.1 \%)$.

3.2. Family Composition and Household Characteristics. Urbanization status was related to the demographic structure of households. Rural-urban residents were much more likely to report residing in a household as "couple without children" (12.6\% in males and $9.2 \%$ in females in the rural-urban group versus 5.9\% among males and $4.9 \%$ among females in the urban-urban group versus $4.8 \%$ among males and $3.3 \%$ among females in the rural-rural group) (Table 2). Slightly more than $60 \%$ of our cohort members were not married and they constituted the largest group with no spouse (Table 1).

Fathers were reported as the most common heads of households across all groups, most in the rural-rural group
(47.9\% among males and 56.0\% among females) and least in the rural-urban group (31.5\% among males and $35.6 \%$ among females) (Table 2). Reporting oneself as head of household was most prominent in the rural-urban group (46.5\% among males and $14.5 \%$ among females) and was least common in the rural-rural group $(26.2 \%$ among males and $6.7 \%$ among females). Mother-led households were reported more often in the urban-urban group than in the other two groups. The majority of cohort members reported having parents in the household and/or adult siblings. However, the rural-urban group was less likely to share the household with parents and/or adult siblings compared to other groups.

3.3. Permanent and Working Home and Travel Time. Housing characteristics, permanent and temporary place of residence, 
TABLE 3: Housing and travel time among Thai cohort members by lifecourse urbanization.

\begin{tabular}{|c|c|c|c|}
\hline \multirow{2}{*}{ Housing and travel time } & \multicolumn{3}{|c|}{ Lifecourse urbanization* (\%) } \\
\hline & Rural-Rural & Rural-Urban & Urban-Urban \\
\hline \multicolumn{4}{|l|}{ Type of house } \\
\hline Detached or semidetached house & 85.1 & 47.3 & 53.0 \\
\hline Shop-front or row-house & 4.7 & 10.0 & 19.0 \\
\hline Town house & 2.3 & 12.7 & 14.9 \\
\hline Flat, apartment, condominium & 5.5 & 26.9 & 9.1 \\
\hline \multicolumn{4}{|l|}{ Ownership of house } \\
\hline Owned by you and/or partner & 14.6 & 11.7 & 11.7 \\
\hline Mortgaged & 4.0 & 10.1 & 8.9 \\
\hline Not own but rent free (living with family) & 69.0 & 39.9 & 60.9 \\
\hline Rented & 6.1 & 28.7 & 13.2 \\
\hline \multicolumn{4}{|l|}{ Vehicle in the household ${ }^{* *}$} \\
\hline Bicycle & 55.2 & 46.1 & 47.0 \\
\hline Motorcycle & 90.0 & 78.2 & 71.8 \\
\hline Car, pick-up, van & 52.2 & 54.9 & 69.3 \\
\hline No vehicle & 2.3 & 6.9 & 5.9 \\
\hline Permanent home and working home & 41.6 & 57.4 & 31.9 \\
\hline \multicolumn{4}{|l|}{ Days/month at permanent home } \\
\hline 1-3 days/month & 22.7 & 10.2 & 16.8 \\
\hline 4-10 days/month & 33.6 & 43.7 & 28.7 \\
\hline$>10$ days/month & 43.8 & 45.9 & 54.5 \\
\hline \multicolumn{4}{|l|}{ Travel time } \\
\hline$<30$ mins & 56.4 & 54.1 & 46.4 \\
\hline 30 mins -1 hour & 20.4 & 23.6 & 27.2 \\
\hline$>1$ hour & 7.1 & 8.3 & 13.0 \\
\hline Do not have to travel & 16.1 & 14.0 & 13.5 \\
\hline
\end{tabular}

*Urbanization group based on residence at age 12 and again when responding to the baseline questionnaire in 2005, column percents for each variable by urbanisation group.

$* *$ Multiple responses allowed.

and travel time to work across all lifecourse urbanization groups are presented in Table 3. Most of the rural-rural group lived in a detached or semidetached house $(85.1 \%$ versus $53.0 \%$ in the urban-urban group). However, for the urban-urban group, living behind a shop front was more common than for other groups $(19.0 \%$ versus $4.7 \%$ in the rural-rural group); urban-urban cohort members were more often living in a townhouse, as well (14.9\% versus $2.3 \%$ in the rural-rural group). Compared to the rural-rural group, the rural-urban cohort members were much more frequently living in flats, apartments, or condominiums (26.9\% versus $5.5 \%)$.

The majority of rural-rural and urban-urban groups reported living in rent free houses (e.g., living with family) but this was less prominent in the rural-urban group. Almost $30 \%$ of the rural-urban group paid rent compared to just $6 \%$ of the rural-rural group. Ninety percent of the rural-rural group had a motorcycle in the household, whereas close to $70 \%$ of the urban-urban group had a car, pick-up, or van in the household. Seven percent of the rural-urban group did not have a vehicle in the household, a higher proportion than for other groups.
The majority of the rural-urban group (57.4\%) reported two homes-a permanent and a working home. A higher proportion of this transitional rural-urban group spent 4 to 10 days per month at their permanent home compared to the rural-rural and the urban-urban groups. Less than 30 minutes travel time to work was reported most often for the rural-rural group (56.4\%), followed by the ruralurban group (54.1\%) and the urban-urban group $(46.4 \%)$. Thirteen percent of the urban-urban group spent more than an hour to get to work which was almost twice the corresponding proportion reported for the rural-rural group.

3.4. Physical, Psychological, and Social Outcomes. We report here selected health and social outcomes by sex and urbanization groups (Table 4). The rural-rural group was less likely to report "poor or very poor" self-assessed health compared to other groups $(3.3 \%$ for males and $4.7 \%$ for females in the rural-rural group versus $4.2 \%$ for males and $5.7 \%$ for females in the rural-urban group versus $4.7 \%$ for males and $5.9 \%$ for females in the urban-urban group). Reporting psychological distress also shows a similar trend with 
TABLE 4: Health and social outcomes by sex and lifecourse urbanisation among Thai cohort members.

\begin{tabular}{|c|c|c|c|c|c|c|}
\hline \multirow{3}{*}{ Social and health outcomes } & \multicolumn{6}{|c|}{ Lifecourse urbanization* (\%) } \\
\hline & \multicolumn{2}{|c|}{ Rural-rural } & \multicolumn{2}{|c|}{ Rural-urban } & \multicolumn{2}{|c|}{ Urban-urban } \\
\hline & Males & Females & Males & Females & Males & Females \\
\hline \multicolumn{7}{|l|}{ Physical and psychological health } \\
\hline Self-assessed health (“poor” or “very poor”) & 3.3 & 4.7 & 4.2 & 5.7 & 4.7 & 5.9 \\
\hline Psychological distress ("most or all the time") & 5.1 & 6.1 & 5.6 & 6.8 & 6.8 & 7.8 \\
\hline Hypertension & 4.3 & 1.8 & 4.8 & 2.2 & 4.5 & 2.2 \\
\hline Depression & 3.4 & 3.0 & 2.9 & 3.8 & 3.4 & 4.1 \\
\hline Body Mass Index $>25$ & 16.8 & 7.6 & 18.4 & 6.7 & 26.2 & 12.5 \\
\hline \multicolumn{7}{|l|}{ Health behaviours } \\
\hline Smoking (current prevalence) & 20.4 & 0.4 & 20.8 & 0.9 & 25.6 & 2.2 \\
\hline Alcohol (current prevalence) & 8.4 & 0.4 & 10.0 & 0.6 & 10.9 & 0.9 \\
\hline \multicolumn{7}{|l|}{ Social indicators } \\
\hline Social trust "people can be trusted" & 64.9 & 64.3 & 60.0 & 56.2 & 57.8 & 59.3 \\
\hline Social interactions_-family (every week) & 51.4 & 67.2 & 21.6 & 28.9 & 61.4 & 71.7 \\
\hline Social interactions—neighbours (every week) & 37.0 & 32.9 & 25.3 & 19.5 & 28.5 & 24.4 \\
\hline Social support_-family (a lot) & 63.0 & 66.9 & 58.5 & 60.0 & 62.6 & 62.8 \\
\hline Social support—neighbours (a lot) & 47.9 & 41.3 & 36.6 & 29.7 & 28.5 & 25.2 \\
\hline
\end{tabular}

* Urbanization group based on residence at age 12 and again when responding to the baseline questionnaire in 2005, column percents for each variable by urbanization group.

proportions highest for the urban-urban group. Current smokers and alcohol consumers were more prevalent among males in the urban-urban group. Current male smokers by groups were as follows: $20.4 \%$ for rural-rural, $20.8 \%$ for rural-urban, and $25.6 \%$ for urban-urban; for females the corresponding prevalences were $0.4 \%, 0.9 \%$, and $2.2 \%$. Social trust was found to be the lowest among females of the rural-urban group (56.2\%) when compared to the urban-urban $(59.3 \%)$ and the rural-rural group (64.3\%). Males in the urban-urban group also reported the least social trust compared to the other two groups (57.8\%). In addition, weekly interactions with family and neighbours were substantially less frequent among the rural-urban group compared to other groups, that is $21.6 \%$ among males and $28.9 \%$ among females in the rural-urban group versus $51.4 \%$ among males and $67.2 \%$ for females in the rural-rural group. The urban-urban group reported the least social support received from neighbours compared to the other two groups.

We also present odds ratios and 95\% confidence intervals based on multivariate analyses of the urbanization effect on self-assessed health, depression and hypertension, adjusting for sociodemographic attributes, health-risk behaviours, and social trust (Figure 1). Poor self-assessed health was prominent in the urban-urban group $(\mathrm{OR}=$ 1.30, 95\% CI 1.17-1.43) and the rural-urban group $(\mathrm{OR}=1.21,95 \% \mathrm{CI} 1.11-1.32)$. Other important covariates also included low social trust $(\mathrm{OR}=2.07$, 95\% CI 1.92-2.23), regular alcohol drinking (OR = $1.85,95 \%$ CI $1.57-2.18$ ), and being divorced/separated or widowed $(\mathrm{OR}=1.33,95 \% \mathrm{CI} 1.11-1.60)$. In addition, it should also be noted that females in both age groups were more likely to report poor self-assessed health. Depression was associated with the urban-urban group $(\mathrm{OR}=1.24$, $95 \%$ CI 1.11-1.40) and the rural-urban group ( $\mathrm{OR}=1.12$, 95\% CI 1.01-1.24); other important covariates included low social trust, being divorced/separated or widowed, belonging to the lowest income group, and smoking. After adjusting for other covariates, hypertension was not significantly associated with urbanization groups but it was influenced by older age and drinking.

Overall, for poor self-assessed health and depression outcomes, urbanization independently and significantly increased the risk after adjusting for the substantial effects of other major risk factors including low social trust, regular drinking, smoking, low income, and marital status as divorced, widowed, or separated.

\section{Discussion}

Overall, our cohort consists of slightly more females than males and there were more single-person households in the rural-urban group, especially among males. Socioeconomic characteristics of cohort members varied substantially according to lifecourse urbanization groups. Unsurprisingly, the rural-urban and the urban-urban groups had higher monthly incomes and more household assets than the ruralrural group.

Household composition and living arrangements differ by lifecourse urbanization. The rural-rural group had the highest proportion of more than 4-person households and generally lived in detached houses. The urban-urban group had the highest proportion of nonmarried cohort members, residing in shop fronts or town houses. The rural-urban group had more one-person households or couple-only households residing in rented flats or apartments, which re- 


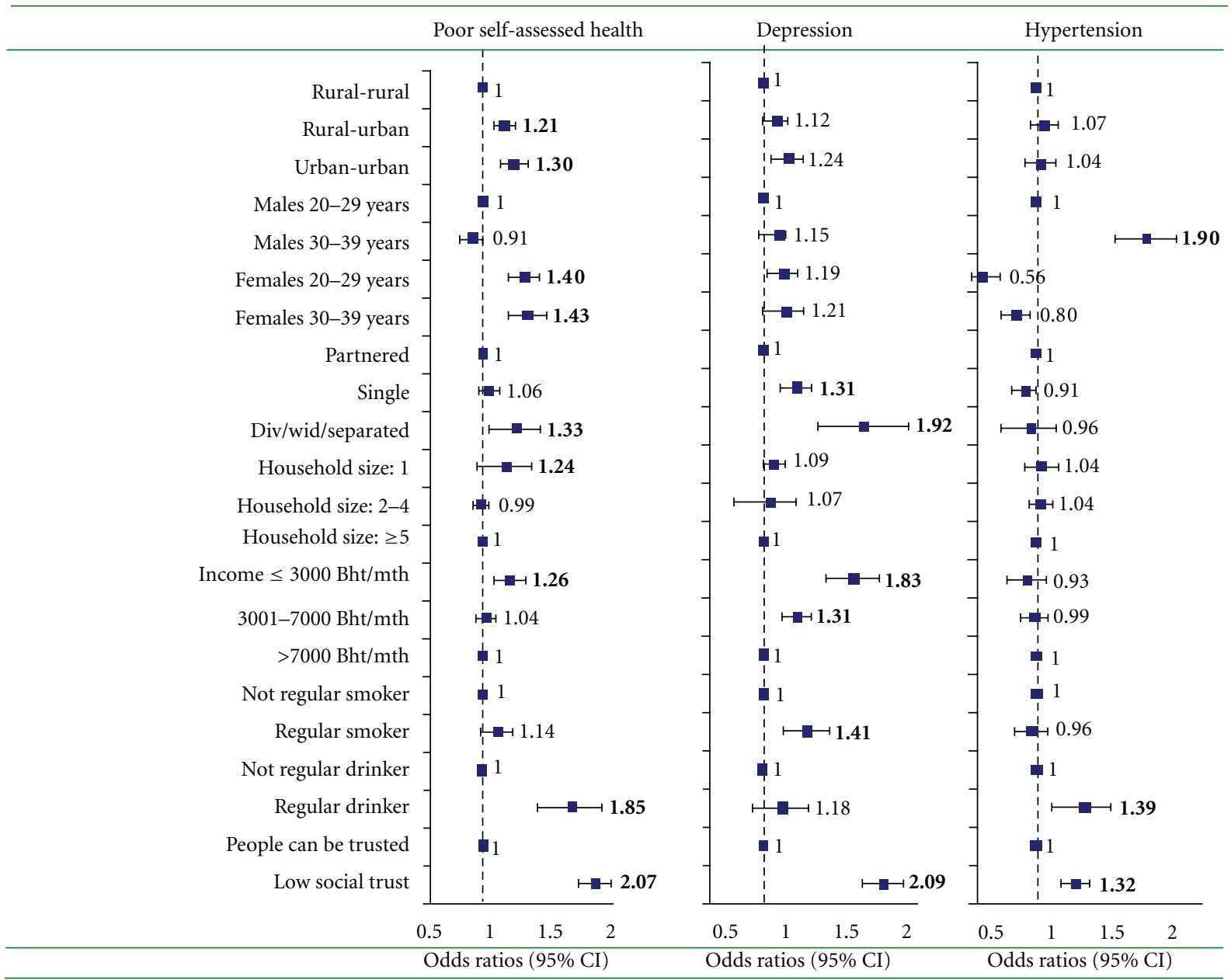

FIgURE 1: Multivariate logistic regression of the association of lifecourse urbanisation with three health outcomes, adjusting for sociodemographic attributes, health behaviours, and social trust among Thai cohort members, 2005.

flects a concomitant housing and social transition for those who migrate from rural to urban areas [28]. In addition, a higher proportion of the rural-urban group had both a permanent, and another home where they stay when working; part of the reason might be to minimize travelling time to work. This restriction of travelling may have an indirect impact on use of health services as there is evidence from this cohort that Bangkok and other urban residents often report not using health services due to the "long waiting time" or because they "could not get time off work" [27].

Here we have noted substantial differences in the household structure linked to lifecourse urbanization and these differences reveal important sociodemographic drivers of the health-risk transition underway in Thailand. Generally, our results are supported by another study on rural-urban migrants in Thailand which reported urbanization-related stress and a reduction in social networks and support are associated with harmful behaviours, especially excessive drinking after the age of 15 years [29]. Also, we noted that urban females had a low smoking prevalence of $2.2 \%$ in our study but this low rate was more than five times higher than the corresponding rate for their rural counterparts, revealing a looming future risk related to urbanization. This aspect of smoking in Thailand has been reported elsewhere [30]. As well, another aspect of our cohort data already published was the tendency for females to report worse self-assessed health than males-a finding commonly noted in other study [22]. We have noted here that the rural-rural and the urban-ur-ban groups often were the two extremes for both exposures and outcomes. The rural-urban group derived some of the health-risk transition determinants from their rural origins as well as from adaptation to stressful urban life with worse self-assessed health, higher prevalence of depression and ob-esity, and more smoking and alcohol drinking.

Our multivariate analysis confirms the independent effect of urbanization after adjusting for a wide array of demographic, economic, and social characteristics that also contribute to the measured health states (overall health, depression but not hypertension). We can see that the urbanization effect independently operates in parallel to the many other sociodemographic variables in the model; presumably lifecourse urbanization as measured in this study reflects other personal and environmental attributes that 
vary according to rural-rural, rural-urban, and urban-urban status. Overall, the rural-urban and the urban-urban groups have worse health outcomes and higher risks for other social variables.

\section{Conclusions}

Thailand has a relatively low level of urbanization but is urbanizing steadily. In this study, three main lifecourse urbanization groups are compared: rural-rural, rural-urban, and urban-urban. Both the urban-urban and the ruralurban groups are shown to be challenged for adverse health risks, poor self-assessed health outcomes, and poor psychological health. Social interaction and support is less prominent for the rural-urban group probably reflecting smaller households and anonymous residence in urban apartments. Urbanization in such middle-income settings has profound implications for household formation, living and transportation arrangements, social networking, and health. This highlights the importance of urbanization as a mediator of the health-risk transition underway in Thailand and in many countries at a similar stage of economic development. Urbanization transmits the sociogeographic changes that are associated with transitions in both healthrisk behaviours and health outcomes.

Health programs responding to the changing disease pattern in Thailand need to focus more on urban health. Multiple government agencies could work together to produce healthy residents of modern cities. Urban residents are particularly vulnerable to adverse effects of calorieactivity imbalance (high body mass index) and would benefit from programs encouraging healthy diets and promoting physical activities. As well, support for community programs is needed to engage urban residents and their neighbours, which could increase social trust and alleviate associated psychological distress. Regular surveillance of urban populations for health-risk behaviours (including smoking, drinking, and low social contact) would help the Thai government for future urban health planning.

\section{Acknowledgments}

This study was supported by the International Collaborative Research Grants Scheme with joint grants from the Wellcome Trust UK (GR071587MA) and the Australian NHMRC (268055). The authors thank the staff at Sukhothai Thammathirat Open University (STOU) who assisted with student contact and the STOU students who participated in the cohort study. The authors also thank Dr. Bandit Thinkamrop and his team from Khon Kaen University for guiding them successfully through the complex data processing. Comments from the editor and reviewer(s) helped us improve the paper. The Thai Cohort Study Team (Thailand: Jaruwan Chokhanapitak, Chaiyun Churewong, Suttanit Hounthasarn, Suwanee Khamman, Daoruang Pandee, Suttinan Pangsap, Tippawan Prapamontol, Janya Puengson, Yodyiam Sangrattanakul, Sam-ang Seubsman, Boonchai Somboonsook, Nintita Sripaiboonkij, Pathumvadee Somsamai, Duan- gkae Vilainerun, and Wanee Wimonwattanaphan; Australia: Chris Bain, Emily Banks, Cathy Ban-well, Bruce Caldwell, Gordon Carmichael, Tarie Dellora, Jane Dixon, Sharon Friel, David Harley, Matthew Kelly, Tord Kjellstrom, Lynette Lim, Anthony McMichael, Tanya Mark, Adrian Sleigh, Lyndall Strazdins, and Vasoontara Yiengprugsawan) has provided assistance throughout the project. (Thailand versus Australia, page 8)

\section{References}

[1] G. W. Jones and P. M. Visaria, Urbanization in Large Developing Countries, Clarendon Press, Oxford, UK, 1997.

[2] T. D. Fuller, J. N. Edwards, S. Sermsri, and S. Vorakitphokatorn, "Housing, stress, and physical well-being: evidence from Thailand," Social Science and Medicine, vol. 36, no. 11, pp. 1417-1428, 1993.

[3] P. Pridmore, L. Thomas, K. Havemann, J. Sapag, and L. Wood, "Social capital and healthy urbanization in a globalized world," Journal of Urban Health, vol. 84, no. 1, pp. i130-i143, 2007.

[4] T. Kjellstrom, S. Mercado, M. Sami, K. Havemann, and S. Iwao, "Achieving health equity in urban settings," Journal of Urban Health, vol. 84, no. 1, pp. i1-i6, 2007.

[5] R. Kojima, "Introduction: population migration and urbanization in developing countries," The Developing Economies, vol. 34, no. 4, pp. 349-369, 1996.

[6] C. Van Hooijdonk, M. Droomers, I. M. Deerenberg, J. P. Mackenbach, and A. E. Kunst, "The diversity in associations between community social capital and health per health outcome, population group and location studied," International Journal of Epidemiology, vol. 37, no. 6, pp. 1384-1392, 2008.

[7] D. L. Dufour and B. A. Piperata, "Rural-to-urban migration in Latin America: an update and thoughts on the model," American Journal of Human Biology, vol. 16, no. 4, pp. 395-404, 2004.

[8] X. Hu, S. Cook, and M. A. Salazar, "Internal migration and health in China," The Lancet, vol. 372, no. 9651, pp. 17171719, 2008.

[9] R. Skeldon, "Urbanization and migration in the ESCAP region," Asia-Pacific Population Journal, vol. 13, no. 1, pp. 3-24, 1998.

[10] D. S. Massey and M. Aysa-Lastra, "Social capital and international migration from Latin America," International Journal of Population Research, vol. 2011, Article ID 834145, 18 pages, 2011.

[11] S. Goldstein, "Urbanization in Thailand, 1947-1967," Demography, vol. 8, no. 2, pp. 205-223, 1971.

[12] M. Krongkaew, Thailand's Industrialization and Its Consequences, Macmillan/St. Martin's Press, New York, NY, USA, 1995.

[13] T. B. Heaton, A. H. Hawley, J. R. Udry, B. Leoprapai, and R. Cardona, "Migration and the transformation of employment and household structures," Singapore Journal of Tropical Geography, vol. 3, no. 1, pp. 34-43, 1982.

[14] R. Skeldon, "Rural-to-urban migration and its implications for poverty alleviation," Asia-Pacific Population Journal, vol. 12, no. 1, pp. 3-16, 1997.

[15] P. G. Warr, Thailand Beyond the Crisis, RoutledgeCurzon, London, UK, 2005.

[16] N. Kmonwatananisa, Thailand's Management of Regional and 
Spatial Development, National Economic and Social Development Board, Bangkok, Thailand, 2008.

[17] J. Knodel, N. Chayovan, and S. Siriboon, "The familial support system of Thai elderly: an overview," Asia-Pacific Population Journal, vol. 7, no. 3, pp. 105-126, 1992.

[18] T. D. Fuller, P. Kamnuansilpa, and P. Lightfoot, "Urban ties of rural Thais," International Migration Review, vol. 24, no. 3, pp. 534-562, 1990.

[19] M. Silverstein, Z. Cong, and S. Li, "Intergenerational transfers and living arrangements of older people in rural China: consequences for psychological well-being," Journals of Gerontology B, vol. 61, no. 5, pp. S256-S266, 2006.

[20] L. L. Y. Lim, T. Kjellstrom, A. Sleigh et al., "Associations between urbanisation and components of the health-risk transition in Thailand. A descriptive study of 87,000 Thai adults," Global Health Action, vol. 2, 2009.

[21] A. C. Sleigh, S. A. Seubsman, C. Bain et al., "Cohort profile: the Thai cohort of 87134 Open University students," International Journal of Epidemiology, vol. 37, no. 2, pp. 266-272, 2008.

[22] S. A. Seubsman, M. J. Kelly, V. Yiengprugsawan, and A. C. Sleigh, "Gender, socioeconomic status, and self-rated health in a transitional middle-income setting: evidence from Thailand," Asia-Pacific Journal of Public Health, vol. 23, no. 5, pp. 742-753, 2011.

[23] B. Tawatsupa, L. L. Y. Lim, T. Kjellstrom, S. A. Seubsman, and A. Sleigh, "The association between overall health, psychological distress, and occupational heat stress among a large national cohort of 40,913 Thai workers," Global Health Action, vol. 3, no. 1, pp. 1-10, 2010.

[24] M. Kanazawa, N. Yoshiike, T. Osaka, Y. Numba, P. Zimmet, and S. Inoue, "Criteria and classification of obesity in Japan and Asia-Oceania," Asia Pacific Journal of Clinical Nutrition, vol. 11, supplement 8, pp. S732-S737, 2002.

[25] P. Webb, C. Bain, and S. Pirozzo, Essential Epidemiology, Cambridge University Press, Cambridge, UK, 2011.

[26] V. Yiengprugsawan, S. Khamman, S. A. Seubsman, L. L. Lim, and A. C. Sleigh, "Social capital and health in a national cohort of 82,482 Open University adults in Thailand," Journal of Health Psychology, vol. 16, pp. 632-642, 2011.

[27] V. Yiengprugsawan, S. A. Seubsman, L. L. Y. Lim, and A. C. Sleigh, "USED and foregone health services among A cohort of 8734 adult open university students residing throughout Thailand," Southeast Asian Journal of Tropical Medicine and Public Health, vol. 40, no. 6, pp. 1347-1358, 2009.

[28] S. Friel, A. J. McMichael, T. Kjellstrom, and T. Prapamontol, "Housing and health transition in Thailand," Reviews on Environmental Health, vol. 19, no. 3-4, pp. 311-327, 2004.

[29] T. Jirapramukpitak, M. Prince, and T. Harpham, "Rural-urban migration, illicit drug use and hazardous/harmful drinking in the young Thai population," Addiction, vol. 103, no. 1, pp. 91$100,2008$.

[30] C. A. Pachanee, L. Lim, C. Bain, S. Wibulpolprasert, S. A. Seubsman, and A. C. Sleigh, "Smoking behavior among 84,315 Open University students in Thailand," Asia Pacific Journal of Public Health, vol. 23, no. 4, pp. 544-554, 2010. 


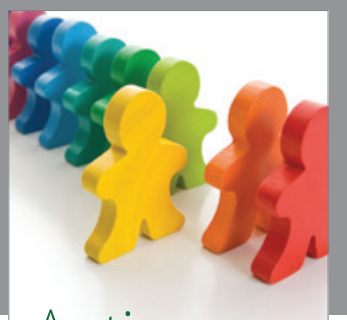

Autism

Research and Treatment
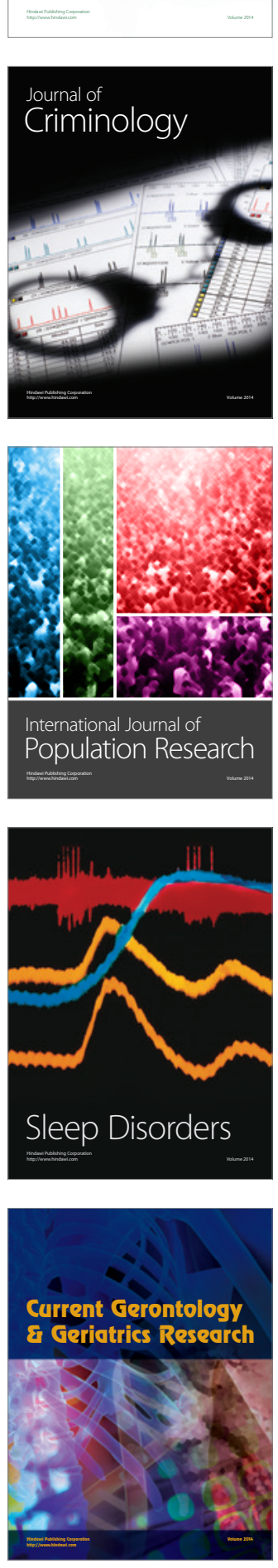
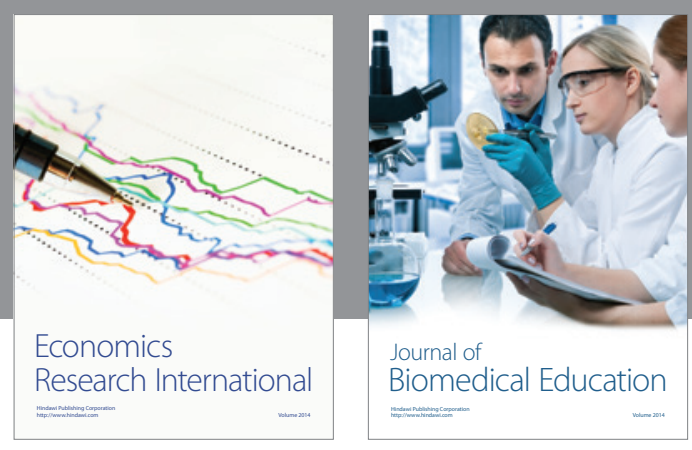

Journal of

Biomedical Education

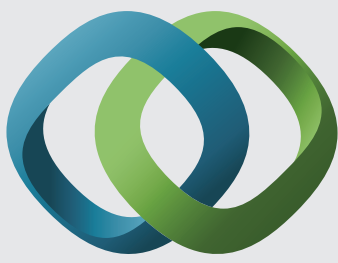

\section{Hindawi}

Submit your manuscripts at

http://www.hindawi.com
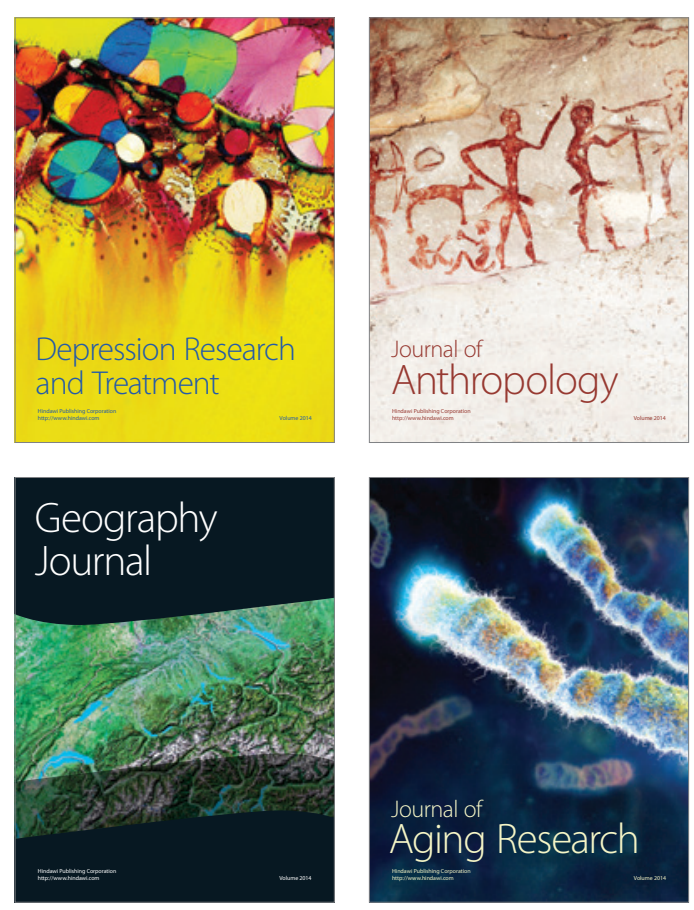

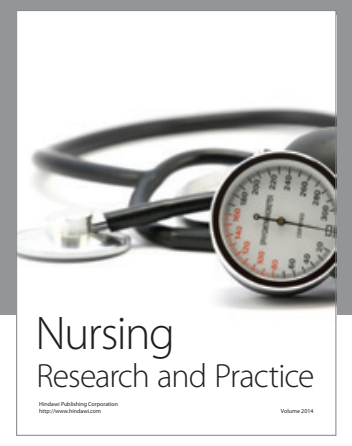

Nursing

Research and Practice

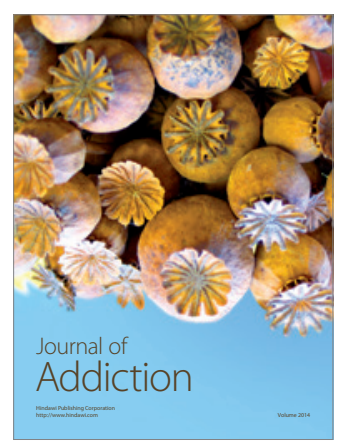

Child Development

Research

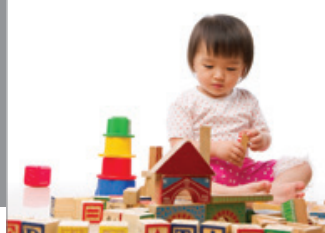

迥
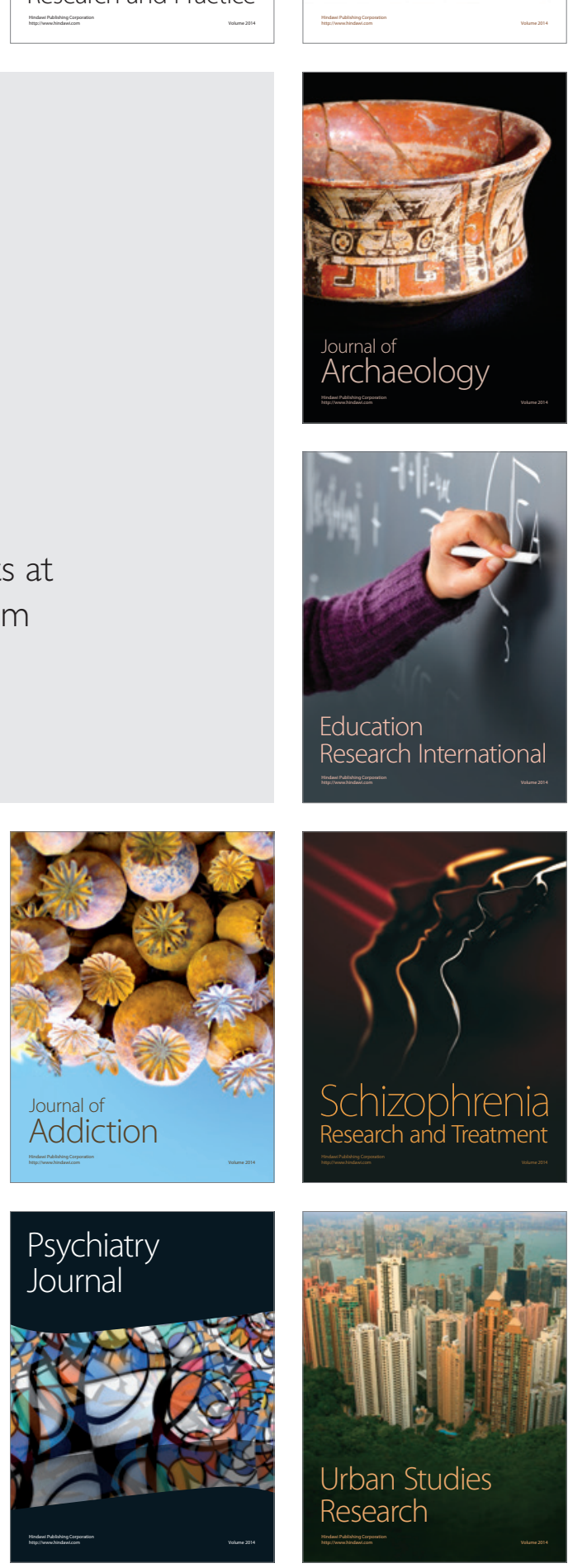